\title{
THE
}

\section{Synthesis of Nucleoside Mono-, Di-, and Triphosphoramidates from Solid-Phase cycloSaligenyl Phosphitylating Reagents}

\author{
Yousef Ahmadibeni \\ University of Rhode Island \\ Rakesh K. Tiwari \\ University of Rhode Island \\ Gongqin Sun \\ University of Rhode Island, gongqinsun@uri.edu \\ Keykavous Parang \\ University of Rhode Island, kparang@uri.edu
}

Follow this and additional works at: https://digitalcommons.uri.edu/bps_facpubs

This is a pre-publication author manuscript of the final, published article.

Terms of Use

All rights reserved under copyright.

\section{Citation/Publisher Attribution}

Ahmadibeni, Y., Tiwari, R. K., Sun, G., \& Parang, K. (2009). Synthesis of Nucleoside Mono-, Di-, and Triphosphoramidates from Solid-Phase cycloSaligenyl Phosphitylating Reagents. Org. Lett. 11(10), 2157-2160. doi: 10.1021/ol900320r

Available at: https://doi.org/10.1021/ol900320r

This Article is brought to you for free and open access by the Biomedical and Pharmaceutical Sciences at DigitalCommons@URI. It has been accepted for inclusion in Biomedical and Pharmaceutical Sciences Faculty Publications by an authorized administrator of DigitalCommons@URI. For more information, please contact digitalcommons-group@uri.edu. 


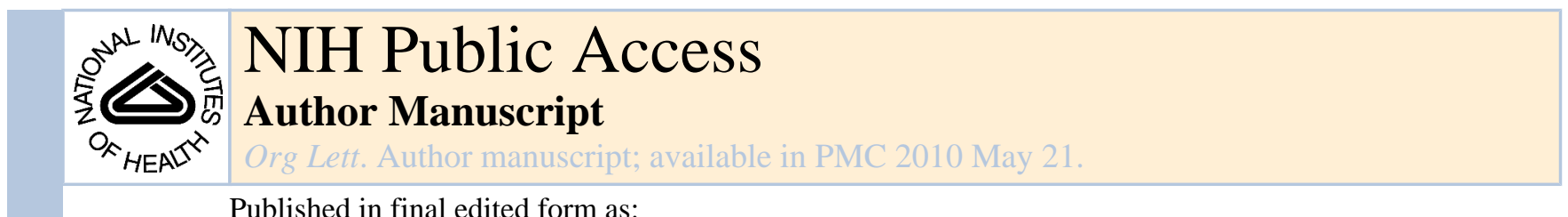

Published in final edited form as:

Org Lett. 2009 May 21; 11(10): 2157-2160. doi:10.1021/ol900320r.

\title{
Synthesis of Nucleoside Mono-, Di-, and Triphosphoramidates from Solid-Phase CycloSaligenyl Phosphitylating Reagents
}

\author{
Yousef Ahmadibeni ${ }^{\mathrm{a}, \mathrm{c}}$, Rakesh K. Tiwaria ${ }^{\mathrm{a}}$, Gongqin Sun ${ }^{\mathrm{b}}$, and Keykavous Parang ${ }^{\mathrm{a}}{ }^{*}$ \\ aDepartment of Biomedical and Pharmaceutical Sciences, College of Pharmacy, The University of Rhode \\ Island, Kingston, Rhode Island 02881 \\ bDepartment of Cell and Molecular Biology, The University of Rhode Island, Kingston, Rhode Island 02881 \\ cDepartment of Chemistry, Columbus State University, Columbus, Georgia 31907.
}

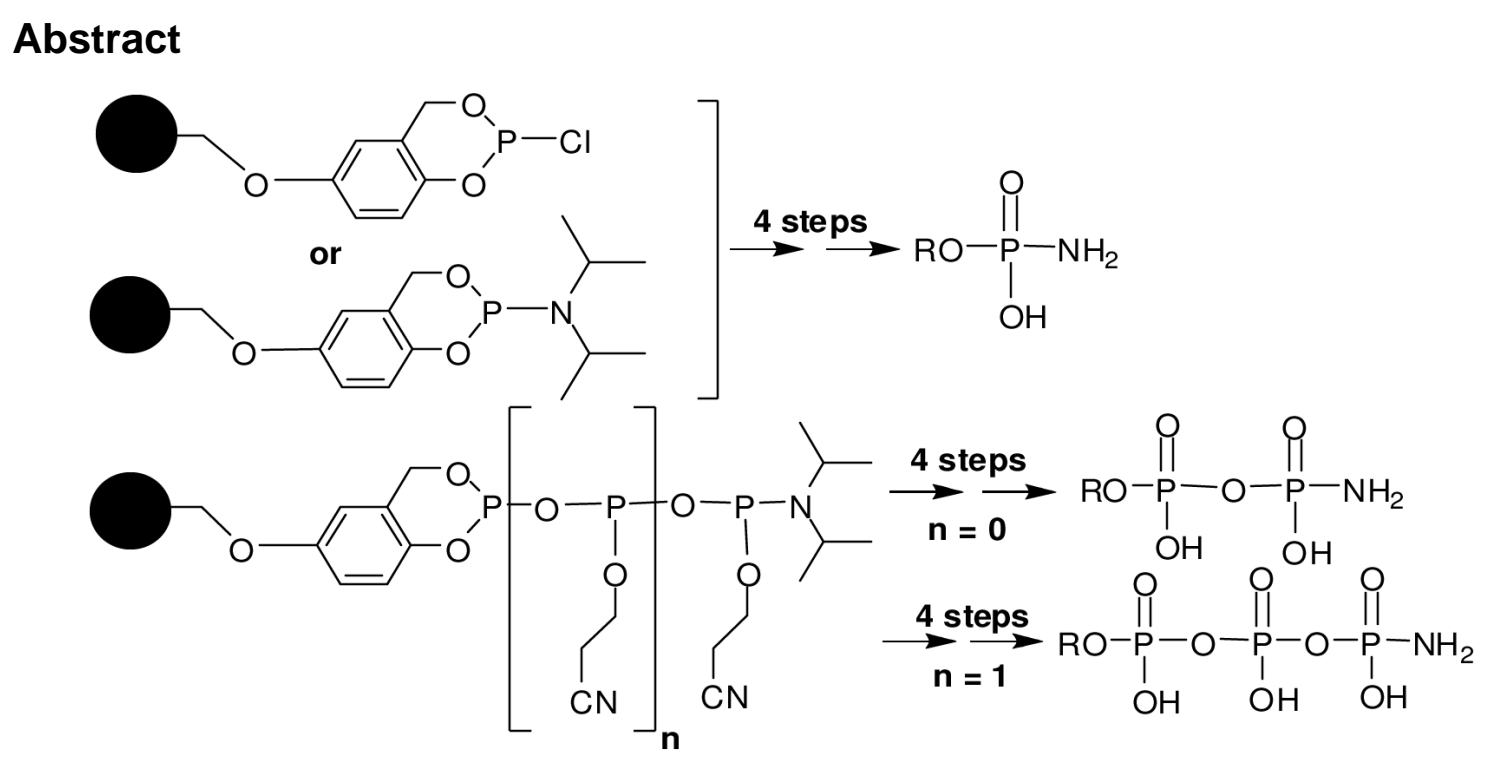

$\mathrm{ROH}=$ (a) 3'-azido-3'-deoxythymidine, (b) adenosine, (c) 3' -fluoro-3' -deoxythymidine, (d) 2',3'-didehydro-2', 3'dideoxythymidine, (e) thymidine, (f) 2'-deoxyadenosine, (g) 2'-deoxycytidine, (h) 2'-deoxyguanidine

Chloromethyl polystyrene resin was reacted with 5-hydroxysalicylaldehyde in the presence of potassium carbonate to afford polymer-bound 2-hydroxybenzaldehyde. Subsequent reduction with borane solution produced polymer-bound 2-hydroxybenzyl alcohol. The reaction of immobilized 2hydroxybenzyl alcohol with appropriate phosphitylating reagents yielded solid-phase cycloSaligenyl mono-, di-, and triphosphitylating reagents, which were reacted with unprotected nucleosides, followed by iodine oxidation, deprotection of cyanoethoxy groups, and the basic cleavage, respectively, to afford 5'-O-nucleoside mono-, di-, and triphosphoramidates in 52-73\% overall yield.

Antiviral and antitumor nucleoside analogs undergo three phosphorylation steps by cellular kinases to generate nucleoside 5 '-triphosphates that act as competitive inhibitors of DNA polymerases or incorporate into DNA and cause chain termination. ${ }^{1}$ The first phosphorylation step is often the rate-limiting step. Thus several nucleoside phosphoramidate derivatives have

*E-mail: kparang@uri.edu.

Supporting Information Available. Experimental procedures and characterization of resins with IR and final compounds with NMR and high-resolution mass spectrometry. This material is available free of charge via the Internet at http://pubs.acs.org. 
been synthesized as prodrugs with the aim of delivering the corresponding 5 '-mononucleotide intracellularly and bypassing the initial phosphorylation step. ${ }^{2-6}$ A number of phosphoramidate derivatives of antiviral and antitumor nucleosides have demonstrated to have enhanced activity and reduced cytotoxicity when compared with their corresponding parent nucleosides. $3,6-8$ Furthermore, oligonucleotide phosphoramidates have attracted considerable attention as potential antisense agents because of their stability toward nucleases and being able to form a duplex with complementary DNA or RNA sequences with higher affinity. ${ }^{9}$,

${ }^{10}$ Catalysis of many hydrolases and nucleases also occur through nucleoside phosphoramidate intermediates. ${ }^{11,12}$ Therefore, the synthesis of nucleoside phosphoramidates and phosphoramidate-based pronucleotides and oligonucleotides are subjects of considerable interest in nucleic acid research. The facile synthesis of larger quantities of phosphoramidate derivatives is essential for studying their biological properties.

The reported solution-phase methods for the synthesis of nucleoside 5'-phosphoramidates include the reaction of nucleoside diphosphates, triphosphates, chlorophosphates, $\mathrm{H}$ phosphonates, or trimethaphosphates, with amines $13-16$ in the presence of a base and/or a coupling reagent (e.g., $N$-carbodiimide derivatives ${ }^{13,17,18}$ or trimethylsilyl chloride ${ }^{15,19}$ ). Alternatively, highly reactive phosphoramidate precursors (e.g., phosphoryldichloride derivatives or bis(benzotriazolyl)phosphoramidates) have been used in reaction with nucleosides for the synthesis nucleoside phosphoramidates. ${ }^{6}$ These methods have one or more disadvantages, such as the requirement for the synthesis of precursor nucleoside phosphates or phosphoramidates, the poor solubility of precursors in organic solvents, tedious purification of final products from intermediates and starting reagents, and low or moderate overall yields. We have previously reported the solid-phase synthesis of nucleoside mono-, di-, and triphosphates with high regioselectivity using polymer-bound linkers of $p$-hydroxybenzyl alcohol or $p$-acetoxybenzyl alcohol. ${ }^{20-4}$

CycloSaligenyl (cycloSal)-phosphate triesters of several nucleoside analogs have been designed as a pH-driven nucleotide delivery system. ${ }^{25-28}$ As part of our ongoing efforts to synthesize organophosphorus compounds, ${ }^{29}$ we report the synthesis of immobilized cycloSal phosphitylating reagents and their application for the synthesis of nucleoside mono-, di-, and triphosphoramidates to circumvent one or more of the problems associated with the solutionphase methods. To the best of our knowledge, this is the first paper on the synthesis of polymerbound cycloSal phosphitylating reagents. Mono-, di-, and triphosphitylating reagents were first immobilized on polystyrene resin-bound linker of 2-hydroxybenzyl alcohol. Coupling reaction of unprotected nucleosides with the immobilized reagent followed by iodine oxidation, deprotection, and basic cleavage afforded nucleoside mono-, di-, and triphosphoramidates.

The advantages of this solid-phase strategy included: (i) The immobilization of hindered phosphitylating reagents on a rigid polymer-bound linker allowed for the regioselective reaction with the most reactive hydroxyl group in the presence of an excess of unprotected nucleosides to afford monosubstituted final products; (ii) Unprotected nucleosides were used instead of precursor nucleoside phosphate derivatives; (iii) Excess of nucleosides and unreacted reagents were removed in each step by washing the resins. Furthermore, the modified linker remained trapped on the resins. This facilitated isolation and purification of monosubstituted final products; and (iv) This strategy allowed the synthesis of nucleoside 5'-O-mono-, di-, and triphosphoramidates from the same polymer-bound linker.

Scheme 1 illustrates the synthesis of diphosphitylating and triphosphitylating reagents (4 and 7). Phosphorus trichloride was subjected to reaction with 3-hydroxypropionitrile (1 equiv) in the presence of 2,6-lutidine in anhydrous THF to yield 2-cyanoethyl phosphorodichloridate (1). The subsequent reaction of $\mathbf{1}$ with diisopropylamine (1 equiv) in the presence of 2,6lutidine afforded 2-cyanoethyl diisopropylchlorophosphoramidite 2. Addition of water (1 
equiv) and 2,6-lutidine gave the intermediate 3 that was reacted with phosphorus trichloride (1 equiv) in the presence of 2,6-lutidine to afford the diphosphitylating reagent $(4,93 \%)$

In a separate reaction, 2-cyanoethyl phosphorodichloridate (1) was reacted with the intermediate $\mathbf{3}$ ( 1 equiv) in the presence of 2,6-lutidine in anhydrous THF to yield $\mathbf{5}$. Compound 5 was immediately treated with water (1 equiv) and phosphorus trichloride (1 equiv), respectively, in the presence of 2,6-lutidine to yield the triphosphitylating reagent $(\mathbf{7}, 87 \%)$.

The diphosphitylating and triphosphitylating reagents (4 and 7) were used immediately in coupling reactions with the polymer-bound 2-hydroxybenzyl alcohol. Compounds 4 and $\mathbf{7}$ were reacted with water and the chemical structures of their dihydroxy forms were confirmed by high-resolution time-of-flight electrospray mass spectrometry.

Scheme 2 shows the synthesis of nucleoside mono-, di, and triphosphoroamidates from polymer-bound 2-hydroxybenzylalcohol (10). Chloromethyl polystyrene resin $(\mathbf{8})$ was reacted with 5-hydroxysalicylaldehyde in the presence of sodium iodide and potassium carbonate to afford polymer-bound 2-hydroxybenzaldehyde (9). Reduction of the aldehyde group in $\mathbf{9}$ in the presence of borane solution (1M) produced polymer-bound 2-hydroxybenzyl alcohol (10), which was reacted with phosphorus trichloride or $N, N$-diisopropyl phosphoramidous dichloride in the presence of 2,6-lutidine to produce the corresponding polymer-bound cycloSal monophosphitylating reagents, $\mathbf{1 1}$ and $\mathbf{1 2}$, respectively.

Similarly, the reaction of $\mathbf{1 0}$ with diphosphitylating and triphosphitylating reagents, $\mathbf{4}$ and $\mathbf{7}$, in the presence of 2,6-lutidine produced polymer-bound cycloSal diphosphitylating and triphosphitylating reagents (13 and 14), respectively. The treatment of $\mathbf{1 1}$ or $\mathbf{1 2}$ with excess of unprotected nucleosides (e.g., 3'-azido-3'-deoxythymidine (a), adenosine (b), 3'-fluoro-3'deoxythymidine (c), 2', 3'-didehydro-2', $3^{\prime}$-dideoxythymidine (d), thymidine (e), 2'deoxyadenosine (f), 2'-deoxycytidine (g), and 3'-deoxyguanidine (h)) in the presence of pyridine or 5-(ethylthio)- $1 H$-tetrazole, respectively, gave 15a-h. Similarly, reaction of $\mathbf{1 3}$ and 14 with excess of 3'-azido-3'-deoxythymidine (a) and adenosine (b) in the presence of 5(ethylthio)- $1 H$-tetrazole afforded 16-17a,b. The most reactive hydroxyl group of unprotected nucleosides reacted selectively with hindered polymer-bound reagents (11-14) when an excess of nucleoside was used in coupling reaction.

Iodine oxidation of 15a-h and 16-17a,b yielded the corresponding polymer-bound nucleosides 5'-O-monophosphate (18a-h), diphosphate (19a,b), and triphosphate triester derivatives $(\mathbf{2 0 a}, \mathbf{b})$. The removal of the cyanoethoxy group with DBU in 19-20a,b afforded the corresponding polymer-bound nucleosides 21-22a,b.

The cleavage of polymer-bound compounds 18a-h and 21-22a,b was carried out under basic conditions $\left(\mathrm{NH}_{4} \mathrm{OH}\right)$. The intramolecular cleavage mechanism of final products from (23a$\mathbf{h}$ and 24-25a,b) is shown in Scheme 2. The cleavage relies on a nucleophilic attack on the phosphate triester by ammonia and a subsequent hydrolysis pathway to yield the nucleoside phosphoramidate derivatives. The reaction of ammonium hydroxide on resin $\mathbf{2 6}$ at the same time produced the linker-trapped resin (27), which was separated from the final products by filtration. The crude products had a purity of $68-92 \%$ and were purified on the $\mathrm{C}_{18}$ Sep-Pak cartridges to afford 5'-O-nucleoside monophosphoramidates, diphosphoramidates, and triphosphoramidates (28a-h, 29-30a,b, Scheme 2) in 52-73\% overall yield (calculated from 11-14, Table S1, see Supporting Information). The products were characterized by ${ }^{1} \mathrm{H}$ NMR, ${ }^{13} \mathrm{C}$ NMR, ${ }^{31} \mathrm{P}$ NMR, and high-resolution mass spectrometry (ESI-TOF).

This is the first report of the synthesis of solid-phase cycloSal phosphitylating reagents and their application for the preparation of nucleoside 5'-O-mono- di-, and triphosphoramidates. The solid-phase strategy allowed facile synthesis and purification of nucleoside 5'- 
phosphoramidate derivatives from unprotected nucleosides by removing the unreacted reagents by washing in each step.

As a typical procedure (Scheme 2), 3'-azido-3'-deoxythymidine (a, 1 mmol, 4 equiv) and 5(ethylthio)- $1 H$-tetrazole (4 equiv) were dissolved in dry DMSO $(3 \mathrm{~mL})$ and were added to swollen 13 (229 mg, $0.25 \mathrm{mmol}, 1.09 \mathrm{mmol} / \mathrm{g})$ in THF (5 mL). The mixture was shaken for $28 \mathrm{~h}$ at room temperature. The resin was collected by filtration and washed with DMSO $(2 \times$ $10 \mathrm{~mL})$ and THF $(2 \times 10 \mathrm{~mL})$, respectively, and dried under vacuum to give 16a $(267 \mathrm{mg})$. Iodine solution in pyridine/water $(98: 2 \mathrm{v} / \mathrm{v})(1.5$ equiv, $1.5 \mathrm{~mL}, 0.5 \mathrm{M})$ was added to swollen resin 16a in THF (5 mL). After 15 min shaking at room temperature, the resin was collected by filtration and washed with pyridine $(2 \times 10 \mathrm{~mL})$, THF $(2 \times 10 \mathrm{~mL})$, and DCM $(2 \times 10 \mathrm{~mL})$, respectively, and was dried overnight at room temperature under vacuum to give $19 \mathbf{a}(273 \mathrm{mg})$. DBU ( $2 \mathrm{mmol}$ ) was added to swollen resin 19a in THF $(5 \mathrm{~mL})$. After $48 \mathrm{~h}$ shaking of the mixture at room temperature, the resin was collected by filtration and washed with THF $(3 \times$ $15 \mathrm{~mL})$ and DCM $(3 \times 15 \mathrm{~mL})$, respectively, and dried overnight at room temperature under vacuum to give $21 \mathbf{a}(244 \mathrm{mg})$. $\mathrm{NH}_{4} \mathrm{OH}(30 \%, 3 \mathrm{~mL})$ was added to swollen resin 21a in THF $(3 \mathrm{~mL})$. After $75 \mathrm{~min}$ shaking of the mixture at room temperature, the resin was collected by filtration and washed with $\mathrm{MeOH}(2 \times 10 \mathrm{~mL})$. The solvents of filtrate solution were immediately evaporated at room temperature. The residue was mixed with Rexyn® $101(\mathrm{H})$ (hydrogen form, $500 \mathrm{mg}, 5.72 \mathrm{meq} / \mathrm{g})$ in water:dioxane $(75: 25 \mathrm{v} / \mathrm{v}, 3 \mathrm{~mL})$ for $15 \mathrm{~min}$. After

filtration, the solvents were removed using lyophilization and the crude products were purified on $\mathrm{C}_{18}$ Sep-Pak using appropriate solvents. The solvents were evaporated and the residues were dried under vacuum at $-20{ }^{\circ} \mathrm{C}$ to yield $29 \mathbf{a}$.

\section{Supplementary Material}

Refer to Web version on PubMed Central for supplementary material.

\section{Acknowledgment}

We acknowledge the financial support from National Science Foundation, Grant Number CHE 0748555. We acknowledge National Center for Research Resources, NIH, Grant Number 1 P20 RR16457 for sponsoring the core facility.

\section{References}

1. Balzarini J. Pharm. World Sci 1994;16:113. [PubMed: 8032337]

2. Parang K, Wiebe LI, Knaus EE. Curr. Med. Chem 2000;7:995. [PubMed: 10911016]

3. Drontle DP, Wagner CR. Mini-Rev. Med. Chem 2004;4:409. [PubMed: 15134543]

4. Cahard D, McGuigan C, Balzarini J. Mini-Rev. Med. Chem 2004;4:371. [PubMed: 15134540]

5. Egron D, Imbach JL, Gosselin G, Aubertin AM, Périgaud C. J. Med. Chem 2003;46:4564. [PubMed: 14521418]

6. Freel Meyers CL, Hong L, Joswig C, Borch RF. J. Med. Chem 2000;43:4313. [PubMed: 11063625]

7. McGuigan C, Cahard D, Sheeka HM, De Clercq E, Balzarini J. J. Med. Chem 1996;39:1748. [PubMed: 8648614]

8. Balzarini J, Egberink H, Hartman K, Cahard D, Vahlenkamp T, Thormar H, DeClercq E, McGuigan C. Mol. Pharmcol 1996;50:1207.

9. Manoharan M. Antisense Nucleic Acid Drug Dev 2002;12:103. [PubMed: 12074364]

10. Chen J-K, Schultz RG, Lioyd DH, Gryaznov SM. Nucleic Acids Res 1995;23:2661. [PubMed: 7651827]

11. Huang K, Frey PA. J. Am. Chem. Soc 2004;126:9548. [PubMed: 15291552]

12. Bieganowski P, Garrison PN, Hodawadekar SC, Faye G, Barnes LD, Brenner C. J. Biol. Chem 2002;277:10852. [PubMed: 11805111] 
13. Parang K, Kohn JA, Saldanha SA, Cole PA. FEBS Lett 2002;520:156. [PubMed: 12044889]

14. Zhu JG, Fu H, Jiang YY, Zhao YF. Synlett 2005:1927.

15. Zhu J, Hua F, Jiang Y, Zhao Y. J. Org. Chem 2006;71:1722. [PubMed: 16468833]

16. Wray J, Jahn W. FEBS Lett 2002;518:97. [PubMed: 11997025]

17. Abraham TW, Kalman TI, McIntee EJ, Wagner CR. J. Med. Chem 1996;39:4569. [PubMed: 8917645]

18. Kruse CH, Holden KG, Offen PH, Pritchard ML, Field JA, Rieman DJ, Bender PE, Ferguson B, Greig RG, Poste G. J. Med. Chem 1988;31:1768. [PubMed: 3045321]

19. Zhu J, Han B, Fu H, Jiang Y, Zhao Z. J. Org. Chem 2005;70:6676. [PubMed: 16095286]

20. Ahmadibeni Y, Parang K. Curr. Protoc. Nucleic Acid Chem 2008:8. [PubMed: 18551427]Chapter 13:Unit 13

21. Parang K, Fournier EJ-L, Hindsgaul O. Org. Lett 2001;3:307. [PubMed: 11430061]

22. Parang K. Bioorg. Med. Chem. Lett 2002;12:1863. [PubMed: 12086835]

23. Ahmadibeni Y, Parang K. J. Org. Chem 2005;70:1100. [PubMed: 15675883]

24. Ahmadibeni Y, Parang K. Org. Lett 2005;7:5589. [PubMed: 16320998]

25. Meier C. Mini-Rev. Med. Chem 2002;2:219. [PubMed: 12370064]

26. Meier C, Meerbach A, Balzarini J. Front. Biosci 2004;9:873. [PubMed: 14766416]

27. Balzarini J, Aquaro S, Knispel T, Rampazzo C, Bianchi V, Perno CF, De Clercq E, Meier C. Mol. Pharmacol 2000;58:928. [PubMed: 11040039]

28. Jessen HJ, Fendrich W, Meier C. Eur. J. Org. Chem 2006:974.

29. (a) Ahmadibeni Y, Parang K. Org. Lett 2005;7:1955. [PubMed: 15876028] (b) Ahmadibeni Y, Parang K. J. Org. Chem 2006;71:5837. [PubMed: 16839180] (c) Ahmadibeni Y, Parang K. Angew. Chem., Int. Ed 2007;46:4739. (d) Ahmadibeni Y, Parang K. Org. Lett 2007;9:4483. [PubMed: 17915884] 


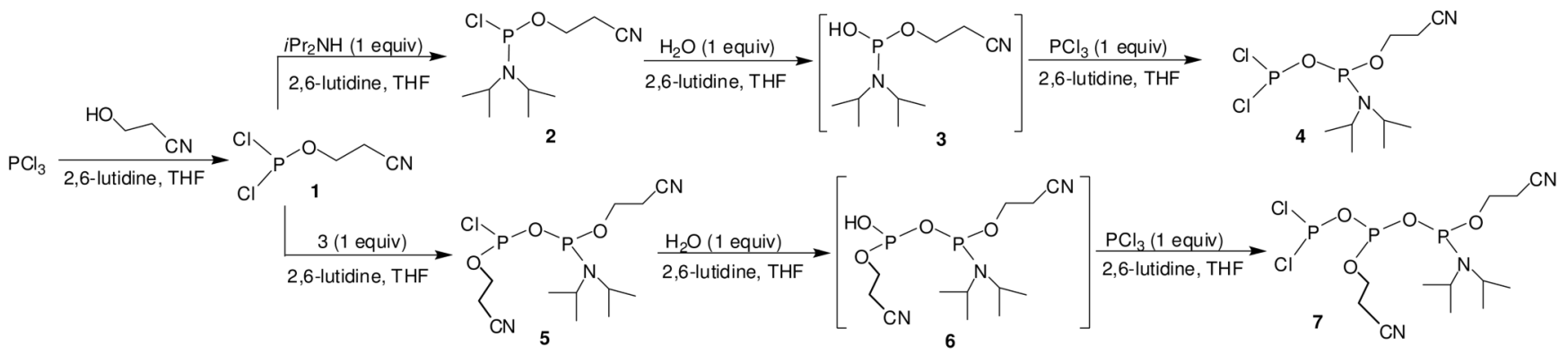

Scheme 1.

Synthesis of Diphosphitylating and Triphosphitylating Reagents (4 and 7). 

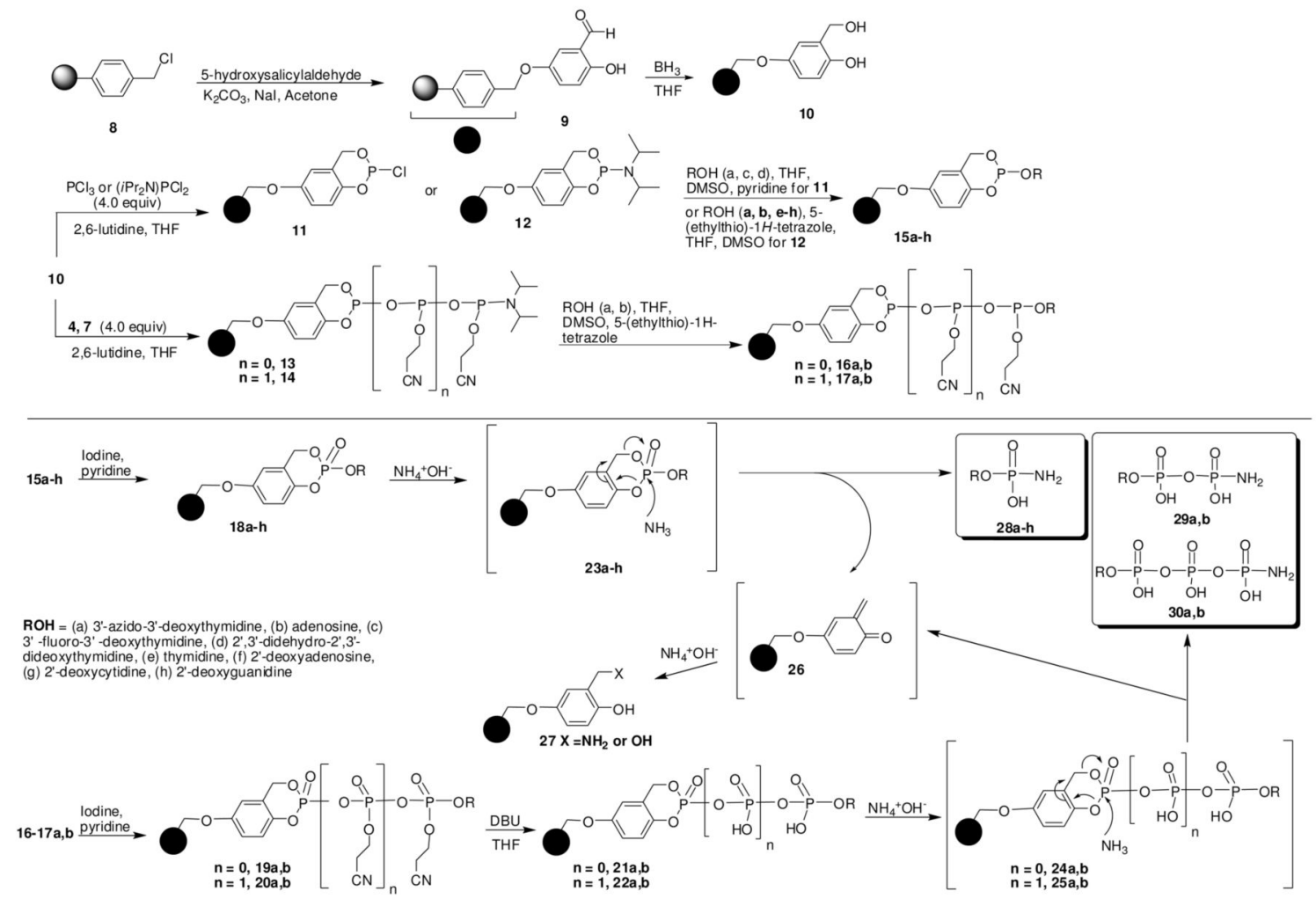

Scheme 2.

Synthesis of Nucleoside Monophosphoramidates 28a-h, Diphosphoramidates, and Triphosphoramidates 29-30a-b on the Solid Phase Using Polymer-Bound Linker 10. 